\title{
Multiple identities and travel mode choice for regular journeys
}

\section{Abstract}

Growing evidence supports a range of non-instrumental factors influencing travel mode. Amongst these, identity has been proposed. However, to date, the relationship has not been systematically investigated and few investigations have harnessed a theoretical framework for identity. Drawing on role theory (Stryker, S., 1980, Symbolic interactionism: A social structural version. CA: Benjamin Cummings), we hypothesised that multiple identities, of varying importance, are related to travel mode choice. The study of 248 UK urban/suburban, working, car-owning parents used survey-based data to test the influence of seven identities on travel mode choice in regular travel. Multiple and logistic regression analyses found multiple identities to be significantly related to travel mode to work, on escort education and on other regular journeys. The study demonstrated different patterns of relationship between identity on different types of journey and found evidence for travel mode choice as embedded within social identities. In addition to the study's contribution of new empirical findings, its application of a theoretical focus on identity offers additional strategies in attempting to change travel behaviours towards sustainability.

\section{Keywords}

Identity; transport behaviour; travel mode choice; regular travel; escort education; commuting 


\section{Introduction}

In attempting to promote low energy behaviour in travel, understanding why people choose particular travel modes is a prerequisite for encouraging behaviour change. For example, private car use, in practical terms, moves people from point of origin to final destination, and speed, convenience and comfort are salient attributes of this mode of travel (Flink, 1975; Gärling, Eek, Loukopoulos, Fujii, Johansson-Stenman, Kitamura, et al. 2002). However, alongside such functional benefits sit psychological factors such as habit (Gärling \& Axhausen, 2003; Verplanken, Aarts, van Knippenberg, \& van Knippenberg, 1994), affective and symbolic motives (Gatersleben, 2007; Steg, Vlek, \& Slotegraaf, 2001; Stokes \& Hallett, 1992), and desires for privacy (Hiscock, Macintyre, Kearns, \& Ellaway, 2002; Mann \& Abraham, 2006) and autonomy (Hiscock, et al., 2002; Ory \& Mokhtarian, 2005). Consideration of travel by car as 'derived demand' alone, that is, as contingent on the primary goal of reaching a destination, may ignore other determining factors. While infrastructure factors such as distance to be travelled and availability of public transport will often constrain travel mode choice, individual choice can still be possible. Psychological factors may help to explain findings such as those of diGuiseppi and colleagues (1998) that attendance at a fee-paying school was significantly related to school travel by car, even when distance from school was controlled. Further, knowledge of psychological factors may propose ways of encouraging changes in travel behaviour towards greater sustainability.

Travel can have positive utility in its own right for many people (Mokhtarian, Salomon, \& Redmond, 2001). One aspect of such positive utility may be the importance of the travel mode to the individual's identity. A number of scholars have suggested such a link (Heffner, Kurani, \& Turrentine, 2007; Mann \& Abraham, 2006; Marsh \& Collett, 1986; Miller, 2001; Steg, et al., 2001) but there has been little attempt to harness existing theories of identity, and little empirical research to examine the relationship between mode choice and identity. The 
current study aims to address these gaps and represents a novel contribution in applying an established theoretical framework on identity (sociological role theory, Stryker, 1980) to choices in regular travel. It is positioned as part of the growing literature which seeks to extend transportation research beyond rational actor (expected utility) models (Gatersleben, 2007;

Gatersleben \& Uzzell, 2007; Heffner, et al., 2007; Klockner \& Blobaum, 2010; Mann \& Abraham, 2006; Steg, 2001).

Recent work has begun to integrate intentional, habitual and situational influences on travel mode choice (Klöckner \& Blöbaum, 2010). There is empirical support for the importance of habit (Gärling \& Axhausen, 2003; Ouellette \& Wood, 1998; Verplanken, et al., 1994). However, although there is broad consensus that past behaviour influences future intention, it has been argued that the relationship could be explained by stable factors influencing both past and future behaviour: habit may be one such factor and identity may be another (Bamberg, Ajzen, \& Schmidt, 2003). An alternative perspective has positioned habit as partially determined by identity. The Self-Reported Habit Index (SRHI), a measure of habit strength, includes an item to tap identity (Verplanken \& Orbell, 2003). Studies using the SRHI, that have found that habit moderates the intention-behaviour relationship (e.g. de Bruijn, Kremers, Singh, van den Putte, \& van Mechelen, 2009; Klockner \& Blobaum, 2010), by implication suggest identity as a factor in travel behaviour. In order to explore the relationship between habit and identity in travel, evidence for the relationship of travel mode choice with identity in its own right represents an initial step. The current research aims to provide preliminary empirical evidence for such a link.

Research on sustainable behaviours such as recycling (Nigbur, Lyons, \& Uzzell, 2010) and 'green' consumption (Sparks \& Shepherd, 1992), and more generally on health related behaviours such as food-related intentions (Dennison \& Shepherd, 1995; Sparks \& Guthrie, 1998; Sparks, Shepherd, Wieringa, \& Zimmermanns, 1995) and eating (Oyserman, Fryberg, \& Yoder, 2007), have argued for a link between identity and behaviour in those domains. In the 
travel literature, several studies, focusing mainly on the choice to drive, have suggested the salience to driving of different aspects of identity. Steg (2005) conceptualised the potential importance of car use to an individual as fulfilling symbolic as well as instrumental and affective needs, and these are argued to be overlapping rather than distinct factors (Lois \& López-Säez, 2009; Mann \& Abraham, 2006). Dittmar (1992) argued that material possessions are imbued with symbolic meanings and these meanings relate to expression of self and of social category. Building on Dittmar's insights, Steg and colleagues (2001, p.164) argued that the car "satisfies the need to express yourself and your social position", and further categorised an underlying dimension of car use as the expression of self-identity that related to freedom.

In Steg's valuable contributions to understanding the needs which a car can fulfil, the conceptualisation of identity is wide-ranging but loosely defined. Steg's identity-related terms appear to refer to self-expression, self-verification, self-presentation, social status, membership of a social group and autonomy. Other studies have demonstrated the relationship of cars to status (Davies, Halliday, Mayes \& Pocock, 1997; Johansson-Stenman \& Martinsson, 2006; Mann \& Abraham, 2006), and their findings support Dittmar's (1992) argument that the ownership of possessions is a mechanism for social approval. Where Steg proposed identity processes involved in car use, Heffner and colleagues (2007) investigated meanings of ownership for one type of vehicle, contributing rich insights into aspects of identity relating to car use more generally. Qualitative research has found that participants drew on identities such as 'motorist' and 'pedestrian' in describing their reaction to travel planning initiatives (Gardner \& Abraham, 2007), and described customising their car or displaying bumper stickers as communicating their identity (Fraine, Smith, Zinkiewicz, Chapman, \& Sheehan, 2007). In a relatively rare study on travel choices other than driving, Gatersleben and Haddad (2009) explored aspects of identity through stereotypical views of cyclists.

In the transport literature then, the term 'identity' has been used for many facets of the self: some of these aspects, such as autonomy, relate to a personal identity, while others, such as 
self-presentation may relate more to a social identity. The proposition that personal and social identities may be considered as varying aspects of the same underlying construct, as argued by Deaux (1992), Breakwell (1986) and others, brings some theoretical coherence to disparate aspects of identity. Nevertheless, we would argue that clearer theoretical conceptualisation of identity is necessary to make progress in understanding its relationship to travel behaviour. A theoretical framework will not only clarify what is meant by identity, or what aspects of identity are considered salient, but will also aid prediction of further relationships or processes. We suggest that sociological role theory (Stryker, 1980, 1987) offers such theoretical conceptualisation.

Sociological role theory defines an identity as the internalisation of a social role, together with its concomitant norms and expectations. Thus an identity is shaped within social networks, and has a personal or subjective reality as the meaning individuals ascribe to their experience of social interactions. People move between a multiplicity of social roles and must manage multiple identities Specific identities may be conflicting (Burke, 2006), requiring strategies for resolution, such as modifying the meaning of one or more identities (Stets \& Harrod, 2004), gradual change to reduce discrepancies (Burke, 2006) or other means. Identities are proposed as being maintained in a salience hierarchy. Identities such as 'parent' or 'woman' are likely to be chronically salient while identities such as 'football fan' may be contextually salient. Because social rules and expectations around a social role are internalised as part of an identity, behaviour, as expression of the identity, will normally be congruent with the role. However, an identity is a subjective interpretation of role expectations and thus an individual's behaviour, although likely to be consistent with social norms, is not determined by them. Further, individuals are motivated to seek verification of central identities (Burke \& Tully, 1977). Sociological role theory therefore potentially offers a theoretically coherent account of processes of self-expression, self-verification, self-presentation and membership of social groups and, crucially, links processes of identity with behaviour. Behaviour will typically align 
with role expectations and may be motivated by a need to verify important identities. Further, the proposition in sociological role theory of a multiplicity of identities suggests that behaviour may be guided by multiple identities, of varying importance. However, with the exception of Gardner and Abraham (2007), previous work on sustainable behaviour has tended to explore identities in isolation: the 'recycler' (Nigbur, et al. 2010), the 'green consumer' (Sparks \& Shepherd, 1992), the driver (Steg, 2001). The current study offers a first attempt to explore quantitatively the link between travel mode choice and multiple identities, as proposed by sociological role theory,

We choose to look at regular journeys, as more likely to reflect everyday identities, and focused on journeys to work, on escort education and on other regular trips. The identities investigated were a mix of identities closely related to travel behaviour and "consensual social roles" (i.e. social roles with a level of consensus on meanings, expectations and norms; Kuhn \& MacPartland, 1954). The identities were motorist and pedestrian, based on Gardner \& Abraham, 2007; cyclist, based on Gatersleben \& Haddad, 2009; public transport user; parent and worker, based on Thoits (1992) and Pleck (1985); and community member, based on Gardner \& Abraham (2007). The research hypotheses were:

H1 Identities associated with travel behaviour vary in importance.

H2 Multiple identities are related to mode choice in regular travel.

The challenges of measuring concepts as complex as identities and identity importance merit some discussion. The difficulty of measuring identity importance has been acknowledged (Grace \& Cramer, 2003). Previous studies have assessed identity importance using a self-report to a direct question, for example, "How important is [identity] in defining who you are?" (Vignoles, Regalia, Manzi, Golledge, \& Scabini, 2006), and "In general, being a [identity] is an important part of my self-image" (Settles, 2004; Yip, 2005). This approach to measurement is underpinned by the theoretical understanding of identity centrality or importance as how an individual wishes to be seen, and as a construct accessible to cognitive processes. Identity 
centrality requires self-awareness, and has been defined as "self-ascribed importance" of an identity (Stryker \& Serpe, 1994, p.19). As such, self-report is appropriate, relating to how individuals wish to be seen by themselves and others. Although current measures cannot yet exclude a risk of social desirability, such a bias is likely to attenuate the relationship of interest between identity and travel behaviour. The psychometric attributes of self-report measures of importance have not yet been strongly established. Nevertheless, based on current theoretical understanding in the literature, a self-report measure of identity importance was used in our study. If importance varies for individuals involved in a particular travel behaviour, this would support travel-related identities as constructs with meanings beyond the behaviour. That is, if a driver identity is rated as unimportant by people who drive, this suggests that a driver identity taps meanings outside of mere behaviour.

A complementary measure of identity importance was also used in the current study. The Twenty Statement Test (Kuhn \& McPartland, 1954) uses an open-format measure, the items of which may then be quantified according to the focus of research. Its open format renders it less sensitive to social desirability bias. The Twenty Statement Test represents an individual's own self-conceptualisation, and shows the differential organisation of self between individuals. It has been extensively used (Cousins, 1989; Grace \& Cramer, 2003; Kanagawa, Cross, \& Markus, 2001; Kuhn and McPartland, 1954; Newman, Duff, Schnopp-Wyatt, Brock, \& Hoffman, 1997). Due to its open format, its psychometric properties have proven difficult to establish (Grace \& Cramer, 2003) but has shown high inter-rater reliability (Grace \& Cramer, 2003) and good construct validity (Triandis, McCuster, \& Hui, 1990; Watkins, Yau, Dahlin, \& Wondimu, 1997). The challenge of measuring identity importance was met in this study by the use of both open-format and closed-scale measures for cross-validation. 


\section{Method}

\subsection{Participants}

The research focus on travel to work and on escort education determined a target sample that worked and had school-age children. Target participants were parents in employment, earning over $£ 25,000$ per annum (approximately $€ 30,000$ ), owning a car and living in urban or suburban locations. The requirement for an urban or suburban location and car ownership was to increase the likelihood of locally available public transport and choices in travel mode. A national team of field researchers collected the data, by 'cold calling' at random households in locations with socioeconomic categories of skilled manual, clerical, junior and intermediate occupations.

Response rate was estimated at $10 \%$. Finally, the requirement for personal earning at or above the national average was based on the possible influence that disposable income may have on flexibility in identity-related behaviours (Tsushima \& Burke, 1999) and on the availability of choice in determining transport mode.

Of the 267 completed questionnaires, $62 \%$ were by women. Participants were aged between 20 and 61, with a mean age of 40. The age of the youngest child ranged from 2 to 17 , with a mean of 10 . Ethnicity was $93 \%$ White or White British, compared to the percentage nationally of $88 \%$ White or White British (ONS, 2010). Of the sample, 28\% earned between $£ 1,000$ and $£ 2,000$ per month (at or below the national average), a further $58 \%$ earned between $£ 2,000$ and $£ 3,000$ and $14 \%$ earned over $£ 3,000$ per month. The above-average income from the sample was in line with the recruitment strategy of seeking relatively more affluent participants.

In this sample, $80 \%$ of work trips were made by car, which is higher than the national average of $71 \%$ for commuting journeys (DfT, 2007). 52\% escort education journeys were by car: this is also higher than 2008 UK survey data (DfT, 2009) for primary school children (43\% travelled by car). In this sample, $71 \%$ of all trips were by car compared with $63 \%$ of all trips nationally in 2006 (DfT, 2009). The higher car use is consistent with the greater affluence of the sample compared to the national average, and research evidence for the tendency of car use to 
follow household income (Dargay, 2007). Furthermore, the participants in the sample lived in households with dependent children and household size has been shown to correlate positively with number of car trips (Kitamura, Mokhtarian, \& Laidet, 1997).

\subsection{Procedure}

The study consisted of a paper questionnaire, completed by participants in their home. The questionnaire was designed to take less than 20 minutes to complete, in order to maximise participation. Participants were assured of anonymity, confidentiality and the right to opt out, and were not offered incentives. The introductory text gave the survey's focus as being "how you travel". No reference was made to identities.

\subsection{Measures}

\subsubsection{Travel Mode Choice}

Travel mode to work, on escort education and on other regular journeys (i.e. at least once a week) was measured by asking for the number of journeys of each type by dominant mode: "Which of the following modes do you usually use to travel to and from work? Choose the mode that you use most of the time. If you use more than one mode, please choose only that mode with which you travel the longest distance. Please enter your usual number of journeys per week. (A return journey counts as 2.)" The measurement of miles travelled had been rejected as potentially more indicative of geographical context (e.g. distance from home to destinations) than of choice. The total number of journeys for each travel mode provided an interval-level variable, allowing analysis by multiple regression. Three travel modes were considered: car, public transport and walking.

\subsubsection{Identity Importance}

\subsubsection{Identity Importance (Scale Measure)}

Identity importance was measured in two ways. The importance of seven identities was measured using an item from Vignoles, Regalia, Manzi, Golledge and Scabini (2006): "How important to you is [identity] in defining who you are?" The item was rated on a seven-point 
scale, anchored at 1 "Not at all important", 4 "Neither important nor unimportant" and 7 "Very important". The inclusion of the mid-point allowed participants the freedom to indicate ambivalence. Seven identities were each measured with the single item, four transport-related identities: motorist and pedestrian, based on Gardner \& Abraham, 2007; cyclist, based on Gatersleben \& Haddad, 2009; and public transport user) and three "consensual” identities (community member, based on Gardner \& Abraham, 2007; parent and worker, found by Thoits (1992) and Pleck (1985) to be central for working parents. This measure was collected towards the end of the questionnaire, and is referred to as the 'scale measure' below.

\subsubsection{Identity Importance (Open Format)}

A second measure of identity importance used the Twenty Statements Test (TST; Kuhn \& McPartland, 1954). To avoid priming, this was the first question presented to participants. The wording of the introductory paragraph proposed by Kuhn and McPartland, was modified slightly to contextualise the measure with respect to personal transport. Participants were asked to "Please write twenty answers to the simple question: "When it comes to how I travel, who am I?' In line with Cousins (1989), identity importance was calculated as the proportion of identity statements referring to a transport mode out of the total identity statements per participant: for example five statements referring to driving out of ten identity statements by the participant gave an importance score for a driver identity of 0.5 ; four statements out of 20 referring to public transport gave an importance score of .2 for an identity of public transport user. The Twenty Statement Test, termed the open-format measure below, balanced the prescribed identities in the closed-scale measure with free format responses which allowed subjective experience to emerge. The presence of identity statements relating to particular travel modes provided an indication of the degree of importance of identities. The relative numbers of identity statements about a particular travel mode, calculated as a proportion, allowed calibration of relative levels of importance of identities. 


\subsubsection{Control Variables}

Participants were asked if their locality had a bus, tram, train or tube service. Four participants did not have access to these services and were excluded from further analysis. All participants except one had at least one car. This participant was excluded from analysis so that all responses in the analysis below were from participants who owned a car and had access to local public transport. Additionally, we controlled for the number of cars per household, and car value, which was calculated by dividing the original value of the highest price car in the household by the car age in years. Car value has been associated with higher car use (Dargay, 2007).

\subsection{Data Analysis}

The dataset was checked for completeness, outliers and normality of variables. In addition to the five cases excluded due to lack of access to public transport and a car, eight cases were excluded due to data quality issues and five further cases were excluded as multivariate outliers. One final case was excluded as the sole motorcyclist. The final dataset on which analyses were conducted comprised 248 cases. Identity importance (scale measure) of the motorist and parent identities was skewed. Although a skewed dependent variable in a multiple regression can unduly weight the minority value, a sample size well above the minimum required can attenuate the bias (Tabachnick \& Fidell, 2001). The minimum number of cases required for the multiple regression here was 138: the actual sample size of around 248, depending on the analysis, was considered adequate to allow for skew and to detect a small-to-medium effect size. In analysing by mode, as there were relatively few journeys by public transport and walking (other than to school), the data were dichotomised into categories of 'Any journeys by public transport/walking' and 'No journeys by public transport/walking'. Journeys by car were categorised as 'All journeys by car' and 'Not all journeys by car', as indicators of choice of travel mode. This enabled additional analysis by logistic regression to evaluate the influence of 
predictors on the probability of using a specific travel mode. Very few values were missing and cases with missing values were deleted pairwise in the analysis.

\section{Categorisation of identity statements}

Cousins' (1989) coding scheme for the Twenty Statement Test was extended to include transport-related identities within the Social Identities category. A set of social and transportrelated identities was defined based on the data. Social identities were: parent, spouse, family member (sibling, adult offspring, grandparent, relative), friend, worker and gender. Transport identities were: driver, public transport user, cyclist and walker. For statements that did not explicitly or implicitly reference an identity but were travel related, six additional categories were created for positive and negative references to driving, public transport and walking or cycling.

Each statement was inspected for reference to the identity categories. Explicit references to transport-related or social identities, for example "I am a car driver" (Participant 31, coded as driver), "I am a mother of two" (P1, coded as parent), were coded accordingly. Where transport activities related to the enactment of social identities, for example, "I am a taxi, ferrying the kids" (P142), these were coded as both transport and social identities, in this example, 'taxi' and 'parent'. Cousins' differentiation of 'qualified identities' was not of relevance in this analysis: "I am a confident driver" (e.g. P184) was coded as 'driver'. Coding was conducted by the first author, and a random set was assessed by the second author and a doctoral student. Initial reliabilities ranged from $r=.82$ to .98 and all discrepancies were resolved following discussion.

\section{Results}

Analysis of identity importance (scale measure) showed that identities associated with transport behaviour, as well as 'consensual' social identities, were perceived as important to the participants' self-definition (see Figure 1). The identities of parent, worker and member of the local community were important to the majority of participants. Their relative importance is 
consistent with earlier findings that parent is ranked very important by most individuals, worker is ranked of lower (though not low) importance and member of the local community or neighbour tends to be ranked in the lowest group for importance (Thoits, 1992, Pleck, 1985). The rating of importance for the transport-related identities in Figure 1 is based on those participants who used the particular mode on their regular journeys, for example, of the participants who indicated that they cycled to work, school or on other regular journeys, $48 \%$ rated the identity of cyclist as important to them. A driver identity was important to the majority (79\%), and the identities of pedestrian, public transport user and cyclist were important to over $40 \%$. A proportion of participants using each travel mode (21\% driving, 52-56\% walking, cycling and using public transport) rated the relevant identity as unimportant. This supports Hypothesis 1, that identities associated with travel behaviour vary in importance.

Fig. 1 Identity Importance: 'How important to you are the following in defining who you are?'

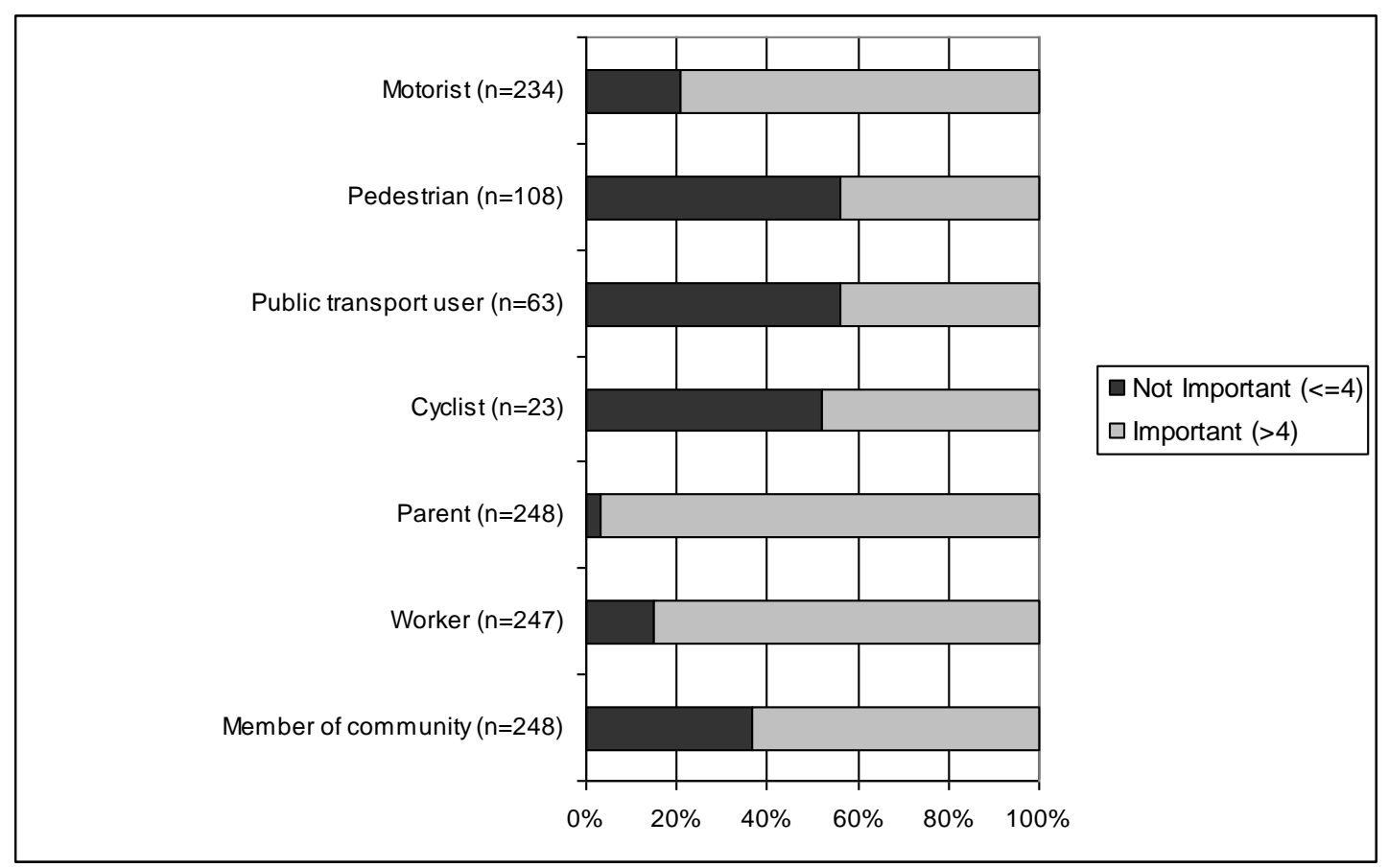

Table 1 shows the means, standard deviations and ranges of the number of journeys by travel mode and type, number of identities per participant, and identity importance. 
Table 1 Means, standard deviations, minima and maxima of main variables $(N=248)$

Mean Std. Dev. Min. Max.

Travel mode

Car

Work: number of journeys

8.88

5.30

0

30

School: number of journeys

4.27

4.87

0

20

Other regular: number of journeys

9.43

7.77

0

60

Public Transport

Work: number of journeys

School: number of journeys

Other regular: number of journeys

Walk

Work: number of journeys

School: number of journeys

Other regular: number of journeys

Total no. of identities per participant

Identity importance - scale [open-format]

$\begin{array}{lllcc}\text { Motorist } & 5.58[.09] & 1.64[.12] & 1[0] & 7[.7] \\ \text { Pedestrian } & 4.07[.01] & 1.73[.02] & 1[0] & 7[.14] \\ \text { Public transport user } & 3.23[.01] & 1.95[.03] & 1[0] & 7[.17] \\ \text { Cyclist } & 2.68[.00] & 1.86[.02] & 1[0] & 7[.14] \\ \text { Parent } & 6.72[.05] & .83[.07] & 1[0] & 7[.33] \\ \text { Worker } & 6.03[.05] & 1.31[.07] & 1[0] & 7[.5] \\ \text { Member of the local community } & 5.00 & 1.51 & 1 & 7\end{array}$

${ }^{\mathrm{a}}$ Identity not referenced by participants on TST.

$\begin{array}{llll}.80 & 2.70 & 0 & 10\end{array}$

$\begin{array}{llll}1.51 & 3.57 & 0 & 10\end{array}$

$\begin{array}{llll}.24 & 1.19 & 0 & 10\end{array}$

$\begin{array}{llll}.36 & 2.06 & 0 & 20\end{array}$

$\begin{array}{llll}3.44 & 4.61 & 0 & 14\end{array}$

$\begin{array}{llll}1.22 & 3.20 & 0 & 20\end{array}$

$\begin{array}{llll}2.17 & 1.5 & 0 & 7\end{array}$


The two measures of identity, scale and open-format, showed, in general, small, positive correlations (driver $18^{.00}$, public transport user $.18^{.00}$, pedestrian $.12^{.05}$, parent $.04^{\mathrm{ns}}$, worker $.13^{.03}$ ) and this is consistent with previous work in which alternative measures of identity were used (Stryker \& Serpe, 1994).

The open-format measure of identity importance, that is, the proportion of responses on the Twenty Statement Test that referred to a particular type of identity, showed that participants referred to multiple identities in thinking about their self-concept with respect to regular travel. The mean number of identities referenced was 2.17, providing initial support for Hypothesis 2, that multiple identities are related to travel mode choice.

The total number of journeys across all journey types (to work, to school and on other regular journeys) was regressed onto demographic and control variables, and importance of identities (scale measure). Regressions were conducted for three modes of travel: car, public transport and walking. Cycling was omitted due to the small number of cycling journeys undertaken. Variables were entered step-wise in two blocks, to investigate the incremental contribution of identities. The first block of variables comprised gender, age, car value and number of cars per household. For school journeys only, the age of the youngest child was also entered. The second block comprised identity importance (scale measure) for: motorist, publictransport user, pedestrian, cyclist, parent, worker and member of the local community. Table 2 presents the results of the regressions and shows the additional variance (Adj $R^{2}$ ) accounted for by inclusion of identities in the regression equations. Across all three travel modes, identities explained an additional 12-13 percentage points of variance. As expected, there were significant relationships between driver identity and car journeys, public transport identity and the use of public transport, and pedestrian identity and walking journeys. In addition, parent and worker identities contributed significant variance to car journeys. Similar patterns were found for the open-format measure of identity importance - for clarity, only the results using the scale 
measure are presented in the tables below. This supports Hypothesis 2, that multiple identities are related to travel mode choice.

Table 2 Multiple regression of number of journeys by travel mode onto identities $\left(B^{p \text { value }}\right)$

\begin{tabular}{llll}
\hline & All Car & All Public & All Walking \\
& Journeys & Transport Journeys & Journeys \\
\hline Motorist & $1.52^{.00}$ & -.23 & -.67 \\
Public transport user & $-1.05^{.02}$ & $.74^{.00}$ & .29 \\
Pedestrian & -.75 & $-.38^{.07}$ & $.76^{.01}$ \\
Cyclist & -.02 & $-.42^{.02}$ & .38 \\
Parent & $-2.77^{.01}$ & -.14 & .15 \\
Worker & $1.46^{.02}$ & .07 & -.44 \\
Member of local comm. & -.38 & .31 & .02 \\
$R^{2}$ & .03 & .06 & .02 \\
$\Delta R^{2}$ & $.13^{.00}$ & $.13^{.00}$ & $.12^{.00}$ \\
Adj. $R^{2}$ & $.12^{.00}$ & $.15^{.00}$ & $.10^{.00}$ \\
\hline
\end{tabular}

Notes:

1. $R^{2}$ is the variance accounted for at Step 1, with only control variables in the model. $\Delta R^{2}$ is the increment in $R^{2}$ when identities are added to the model. Adj. $R^{2}$ is the adjusted $R^{2}$ of the final model which includes identities.

2. Significance at $p<.10$ presented.

3. For Public transport journeys, 74\% of values were 0 so low statistical power should be assumed. For Walking journeys, 55\% =0; for Car journeys, $2 \%=0$.

4. Control variables non-significant with the following exceptions:

For Car journeys: age $B=-.23, p=.02$.

For Public transport journeys: age $B=.10, p=.01$.

For Walking journeys: car value $B=-1.50, p=.03$. 
Table 3 Logistic regression by travel mode category ${ }^{a} \&$ journey type onto identities $\left(\mathrm{B}^{\mathrm{p} \text { value }}\right.$ )

\begin{tabular}{|c|c|c|c|c|c|c|c|c|c|}
\hline & \multicolumn{3}{|l|}{ Car } & \multicolumn{3}{|c|}{ Public Transport } & \multicolumn{3}{|l|}{ Walk } \\
\hline & Work & School & Other & Work & School & Other & Work & School & Other \\
\hline$\%(\mathrm{n}=240)$ & 81 & 44 & 25 & 11 & 16 & 6 & 6 & 38 & 18 \\
\hline Motorist & $.24^{.03}$ & -.03 & $.22^{.03}$ & $-.30^{.02}$ & .20 & .04 & .02 & -.05 & $-.28^{.01}$ \\
\hline PT user & $-.41^{.00}$ & -.12 & -.13 & $.52^{.00}$ & $.23^{.05}$ & $.64^{.00}$ & .24 & .05 & -.01 \\
\hline Pedestrian & -.19 & -.09 & -.04 & .03 & -.18 & -.30 & $.70^{.01}$ & .16 & .15 \\
\hline Cyclist & .07 & -.11 & $-.17 .^{08}$ & $-.28^{.05}$ & -.17 & -.03 & .03 & .11 & .06 \\
\hline Parent & -.21 & -.28 & .20 & .15 & -.10 & .01 & .11 & $.40^{.09}$ & -.18 \\
\hline Worker & .12 & $.22^{.07}$ & .10 & -.14 & .10 & -.15 & -.39 & $-.26^{.03}$ & -.22 \\
\hline Member of & .15 & .12 & .01 & $-.30 .^{08}$ & $.29^{.07}$ & .00 & -.07 & -.06 & .03 \\
\hline local co & & & & & & & & & \\
\hline
\end{tabular}

Notes.

a. Travel modes categorised as: All journeys by car $v$ Not all; Any journeys by public transport v none; Any journeys walking $v$ none. \% in first category presented

b. Significance at $p<.10$ presented.

c. Public transport/Other significant at $p=.07$. All other models significant at $p<.05$

d. Cox \& Snell $R^{2}$ range: .08-.15. Nagelkerke $R^{2}$ range: .14-.35.

e. Control variables non-significant with the following exceptions:

For Car/School, child's age B =-.14, $p=.00 ;$ car value $.42, p=.08$.

For Public transport/School, child's age $B=-12, p=.07$.

For Walk/Work, household cars $B=-1.03, p=.06$; car value $B=2.17, p=.05$.

For Walk/School, car value B $=.75, p=.00$.

For Walk/Other regular travel, gender $B=.78, p=.07$. 
The data were then analysed by journey type, using logistic regression ${ }^{1}$. Table 3 presents the results.

The expected relationships between motorist identity and car use, public transport user and public transport, and pedestrian identity and walking were generally in evidence, although the pattern varied between types of journey (see Table 3). A stronger identity as a motorist was positively related to use of the car for travel to work and on other regular journeys, and was negatively related to the use of public transport for work and walking on other regular journeys. However, a motorist identity was not related to school travel whereas stronger identities of parent and member of the local community were positively related to walking (parent) and taking public transport (member of local community) to school. A stronger identity as a user of public transport was positively related to using public transport on all journey types, and negatively related to use of the car for work. A stronger worker identity was positively related to driving to school, and negatively related to walking to school. Of the control and demographic variables, car value and child's age had significant influence on school journeys.

Multiple regressions were additionally conducted for the three journey types undertaken by car. The pattern of results was very similar to the logistic regressions. A stronger motorist identity was significantly and positively related to car use for work and on other regular journeys, and a stronger identity as a user of public transport was negatively related to commuting by car. A stronger worker identity was again positively related to driving to school

Both multiple regressions of the number of journeys, and logistic regressions of the probability of use of a specific travel mode, supported Hypothesis 2 that identities are related to mode choice in regular travel, and that multiple identities are related to travel model choice.

\section{Discussion}

This study of 248 working parents in England, who lived in urban or suburban settings, owned a car and earned mainly above the average wage, found evidence for the relationship of

\footnotetext{
${ }^{1}$ Data for public transport and walking were too skewed for multiple regression as explained in Section 2.4.
} 
identities to travel mode choice. Specifically, the hypotheses that multiple identities are related to travel behaviour on regular journeys, and that identities associated with travel behaviour vary in importance, were supported. The findings provide evidence that a range of identities predict travel mode to work, on escort education and on other regular journeys. The pattern of the relationships between identities and choice of transport varied across types of journey.

The variance of travel mode choice explained by identity was modest, at 12 or $13 \%$. This is consistent with the body of research on travel mode choice, which has suggested that instrumental factors and environmental affordances are major influences (Flink, 1975; Gärling et al., 2002), and that intention and situational factors affect travel behaviour (Klöckner \& Blöbaum, 2010). The current study shows that identities are factors in the complex web of influences on travel mode. Further research is needed on the relationship between identities and other predictors. In particular, as discussed briefly above, identity may contribute to habit or previous behaviour and future studies should explore this relationship. Although the discussion following focuses on identity motivations in travel, this is with recognition that other instrumental, affective and symbolic influences on mode of travel choice have been demonstrated (Gatersleben, 2007; Gärling \& Axhausen, 2003; Steg, et al., 2001; Verplanken, et al., 1994). The import of identity as a factor in travel mode choice lies in its theoretical importance for behaviour change, which is a desired outcome for reducing greenhouse gas emissions. The results here suggest complex relationships between identities and travel mode. The probability of driving or taking public transport to work was related to the strength of the motorist identity. However, this was not the case for escort education where parent, worker and member of the local community, but not driver, identities were significant. Controlling for gender and child age, the results indicated that the stronger the parent identity, the more likely was walking for escort education. Conversely, the stronger the worker identity, the more likely was driving and the less likely was walking to school. The different patterns of relationship between travel mode and worker and parent identities suggest that travel mode choice may be 
part of negotiating the possibly competing demands of being a worker and a parent, in line with theoretical proposals of multiple and potentially competing identities (Burke, 2006).

If time pressure requires getting to work on time, and being a worker is a central identity, then driving may be the preferred travel mode, but if a parent identity is stronger, then walking a child to school may be chosen. Such a relationship exemplifies the management of multiple identities and implies that behaviour in one domain, such as travel on escort education, may be influenced by identities that are most salient in other domains. In particular, the findings here suggest that the car may offer a way of satisfying the requirements of both worker and parent identities, at certain times. More generally, where identities have potential for temporal conflict, the car may offer a way for avoidance of conflict and for successful management of multiple identities. This understanding leads then to other possibilities for meeting such identity needs: policies on co-ordinating work start times for parents and school start times for children could offer alternative means of avoiding temporal identity conflicts (an approach trialled in some parts of Germany and Italy, Reisch, 2001). Further alternatives may emerge from sociological role theory's proposition of different strategies to resolve conflicting identities. Interventions which make different identities salient, or which aim to modify the meaning of particular identities, may be feasible: emphasising the importance as a parent of walking a child to school may be one such approach.

A further significant relationship between a 'consensual' social identity and travel mode was that of an identity as a member of the local community, which was positively related to using public transport on the school run. The findings are consistent with earlier empirical work (Gardner \& Abraham, 2007) and suggest that social identities merit further exploration. A somewhat anomalous finding in the current data was a negative relationship between identity as a member of the local community and use of public transport for work. It is feasible that a stronger community identity may relate to relating to working within the locality, and hence a short commute precluding use of public transport. However, further investigation is needed. In 
general, the relationship of identities such as parent, worker and member of local community with travel mode choice points to regular travel as embedded in social behaviour. To be a parent, worker or community member entails expectations from, responsibilities to and interactions with others. Recognition of the social nature of travel decisions echoes McMillan's (2005) argument that travel mode is a household, rather than an individual, choice. Although this embeddedness may make change more difficult, the proposal that multiple identities may be related to travel mode choice offers alternative avenues for change. For example, if walking a child to school has meanings associated with being a good parent, or part of verification of a parent identity, interventions which emphasise these meanings may facilitate 'greener' school travel. If ensuring one's child travels to school using public transport is related to perceiving oneself as a member of the local community, interventions which emphasise this relationship may be more successful. Understanding the relative importance of social and transport-related identities which are related to travel mode choice opens up possibilities for encouraging more sustainable behaviour.

Overall, the findings demonstrated the applicability and usefulness of sociological role theory as a framework within which to explore identities. The theory's predictions of multiple identities, of varying importance of identities, of the social nature of identities and of the relationship between identities and behaviour are borne out by the results. Further, the theory points to additional questions to explore, of potential theoretical and practical importance. How do people manage conflicting identities around travel behaviour, for example, a parent with an identity as a walker living some distance from school? What expectations and meanings exist around travel-related identities?

Identities such as parent and worker have been explored extensively (e.g. Johnston \& Swanson, 2006; Stone, 2003; Tsushima \& Burke, 1999) and some of the expectations, norms and typical behaviours of these social identities may be intuitively obvious. In contrast, identities associated with activities such as driving are as yet underexplored. The meaning of 
such identities moves beyond the obvious association between an identity and a specific behaviour. To say "I am a driver" can mean much more than "I drive", as indicated by the results above on the varying importance of identities. A driver identity may position an individual several rungs up the socioeconomic ladder, and may imply a level of wealth and power. It can speak to a specific competence (driving) and more general competences (route finding; administrative ability to maintain paperwork on ownership, licensing, tax and insurance; basic mechanical aptitude to arrange maintenance and refuelling). A driver identity can describe aspects of personality, such as independence, and life stage, with implications of being an adult, a member of society, likely to be in employment, and likely to be involved in social networks of family and friends. These meanings are illustrative - more work is needed on the expectations, norms and meanings associated with identities such as driver and public transport user. However, a driver identity meets the criterion suggested by Devine-Wright and Clayton (2010) that an identity should have implications for cognitive processing. Their suggestion that stereotypes can indicate cognitive shortcuts for identities is fulfilled by such stereotypes, common in the UK, as "BMW driver" or "white van man". Deeper understanding of the meanings associated with transport-related identities offers the potential for more effective interventions to encourage sustainable behaviour. An approach such as motivational possible selves (Markus \& Nurius, 1986) may offer an identity-based way forward.

Such approaches may be particularly salient given the negative, significant relationship found in the results above between a public transport user identity and use of the car for travel to work. The results suggested that the stronger an identity as a public transport user, the lower the likelihood of using a car to travel to work and the greater the likelihood of using public transport for work, school and other regular journeys.. It is worth noting that only $26 \%$ of participants made at least some regular journeys by public transport, thus there is extensive scope for seeking to increase the positive meanings for identities relating to use of public transport. One possible way may be to encourage any use of public transport. Earlier studies 
(e.g. Fujii \& Kitamura, 2003) have shown that incentives to use public transport resulted in changed behaviour (increased use of public transport), even when the incentives were withdrawn. This contradicts other findings (e.g. Aronson \& Gonzales, 1990) that changed behaviour does not tend to outlast the delivery of an incentive. We suggest that increased use of public transport may lead to changes in travel-related identity, and specifically in increased importance of a public transport identity. Future research should examine identity importance as a mediator between such incentives and changed behaviour.

A number of limitations of the current study are acknowledged. A single-item measure of identity importance, with the neutral mid-point labelled as 'Neither important nor unimportant', represents a weakness of the study. The difference between 'Not at all important' and 'Neither important nor unimportant' may have been confusing for participants.

Nevertheless, using two measures of identity which showed similar results increased confidence in our findings. For future research, a unipolar scale of importance may provide a stronger measure and, ideally, a multi-item scale with established validity and reliability is required, with further understanding of the risk of social desirability bias. With self-reports, there can be a risk of consistency bias but the very different formats used are likely to have reduced potential risk (and indeed, although there are positive and significant correlations between corresponding measures from the open and scale formats, the magnitudes of those correlations are small). The measure of travel mode includes both mode choice and number of trips and could be improved by clearly distinguishing between these measures. In addition, the wording of this measure may have been interpreted either as number of journeys by dominant mode or the total number of journeys by journey type. Although both interpretations provide a measure of travel mode, more precise measurement would aid stronger results. In using cross-sectional data, the study cannot answer questions on directionality of influence: the directionality of the relationship between identities and travel mode choice has yet to be explored. While identities may influence travel mode choice, the relationship could be reciprocal or even reversed for mode- 
related identities: driving a car may lead to a stronger motorist identity. While acknowledging the complexity of factors which may influence travel mode choice, the study analysed relatively simple models. Future work should consider additional factors, including habit, values, perceived behavioural control, and attitudes, and more socio-demographic factors such as income and household size. Qualitative studies, in particular, may add to understanding of processes. The study's focus on the work commute and escort education limited the sample to working parents. To generalise, further investigations should be done with non-working adults and adults without dependent children. The study targeted participants who earned at or above average income, and who lived in urban or suburban areas where public transport was more likely to be available: both of these factors were intended to ensure that the participants potentially had alternative travel modes. The findings should be understood within the limitations that, although identities may influence travel mode choice, this is only possible when choice exists. Geographic location, level of affluence, availability of public transport, and other social structural and environmental structural factors may ultimately determine travel mode.

In conclusion, the study demonstrated that multiple identities are related to travel mode choice on regular journeys. As such, the influence of identities should be included in the complex mix of factors affecting travel behaviour. The influence of identities may vary across type of journey. The application of a theoretical focus on identity offers the potential for additional strategies in attempting to change travel behaviours towards sustainability.

\section{Acknowledgements}

This research was partially funded by the ESRC Research Group on Lifestyles, Values and Environment (RESOLVE) (Grant No. RES-152-25-1004). The authors would like to thank two anonymous reviewers whose extensive comments have helped us in our thinking and articulation of our research. 


\section{References}

Aronson, E., \& Gonzales, M. H. (1990). Alternative social influence processes applied to energy conservation. In J. Edwards, R. S. Tindale, L. Heath \& E. J. Posavac (Eds.), Social influence processes and prevention (pp. 301-325). New York: Plenum.

Bamberg, S., Ajzen, I., \& Schmidt, P. (2003). Choice of Travel Mode in the Theory of Planned Behavior: The Roles of Past Behavior, Habit, and Reasoned Action. Basic \& Applied Social Psychology, 25(3), 175.

Breakwell, G. (1986). Coping with threatened identities. London: Methuen.

Burke, P. J. (2006). Identity Change. Social Psychology Quarterly, 69(1), 81-96.

Burke, P. J., \& Tully, J. C. (1977). The measurement of role identity. Social Forces, 55(4), 881897.

Cousins, S. D. (1989). Culture and self-perceptions in Japan and the United States. Journal of Personality and Social Psychology, 56(1), 124-131.

Dargay, J. (2007). The effect of prices and income on car travel in the UK. Transportation Research Part A, 41(10), 949-960.

Davies, D. E., Halliday, M. E., Mayes, M., \& Pocock, R. L. (1997). Attitudes to cycling: a qualitative study and conceptual framework. Wokingham, Berks: Transport Research Laboratory.

de Bruijn, G.-J., Kremers, S. P. J., Singh, A., van den Putte, B., \& van Mechelen, W. (2009). Adult active transportation: Adding habit strength to the theory of planned behavior. American Journal of Preventive Medicine, 36(3), 189-194.

Deaux, K. (1992). Personalizing identity and socializing self. In G. Breakwell (Ed.), Social psychology of identity and the self-concept (pp. 9-33). London: Surrey University Press.

Dennison, C. M., \& Shepherd, R. (1995). Adolescent food choice - an application of the theory of planned behaviour. Journal of Human Nutrition and Dietetics, 8(1), 9-23. 
Devine-Wright, P., \& Clayton, S. (2010). Introduction to the special issue: Place, identity and environmental behaviour. Journal of Environmental Psychology, 30(3), 267-270.

DfT. (2007). Travel to work: Personal travel factsheet July 2007. London: Office for National Statistics/Department for Transport.

DfT. (2009). National Travel Survey 2008. London: Office for National Statistics/Department for Transport.

DiGuiseppi, C., Roberts, I., Li, L., \& Allen, D. (1998). Determinants of car travel on daily journeys to school: Cross sections survey of primary school children. British Medical Journal, 316, 1426-1428.

Dittmar, H. (1992). The social psychology of material possessions: To have is to be. Hemel Hempstead: Harvester Wheatsheaf.

Flink, J. J. (1975). The Car Culture. Cambridge, MA: MIT Press.

Fraine, G., Smith, S. G., Zinkiewicz, L., Chapman, R., \& Sheehan, M. (2007). At home on the road? Can drivers' relationships with their cars be associated with territoriality? Journal of Environmental Psychology, 27, 204-214.

Fujii, S., \& Kitamura, R. (2003). What does a one-month free bus ticket do to habitual drivers? An experimental analysis of habit and attitude change. Transportation, 30(1), 81-95.

Gardner, B., \& Abraham, C. (2007). What drives car use? A grounded theory analysis of commuters' reasons for driving. Transportation Research Part F: Traffic Psychology and Behaviour, 10(3), 187-200.

Gatersleben, B. (2007). Affective and symbolic aspects of car use. In T. Gärling \& L. Steg (Eds.), Threats from car traffic to the qualify of urban life (pp. 219-233). Oxford: Elsevier.

Gatersleben, B., \& Haddad, H. (2009). Who is the typical bicyclist? Transportation Research Part F: Traffic Psychology and Behaviour, 13(1), 41-48. 
Gatersleben, B., \& Uzzell, D. (2007). Affective appraisals of the daily commute: Comparing perceptions of drivers, cyclists, walkers, and users of public transport. Environment and Behavior, 39(3), 416-431.

Grace, S. L., \& Cramer, K. L. (2003). The elusive nature of self-measurement: The selfconstrual scale versus the TST. Journal of Social Psychology, 143(5), 649-668.

Gärling, T., \& Axhausen, K. W. (2003). Introduction: Habitual travel choice. Transportation, $30,1-11$.

Gärling, T., Eek, D., Loukopoulos, P., Fujii, S., Johansson-Stenman, O., Kitamura, R., et al. (2002). A conceptual analysis of the impact of travel demand management on private car use. Transport Policy, 9(1), 59-70.

Heffner, R. R., Kurani, K. S., \& Turrentine, T. S. (2007). Symbolism in California's early market for hybrid electric vehicles. Transportation Research Part D, 12, 396-413.

Hiscock, R., Macintyre, S., Kearns, A., \& Ellaway, A. (2002). Means of transport and ontological security: Do cars provide psycho-social benefits to their users? Transportation Research Part D-Transport and Environment, 7(2), 119-135.

Johansson-Stenman, O., \& Martinsson, P. (2006). Honestly, why are you driving a BMW? Journal of Economic Behavior \& Organization, 60, 129-146.

Johnston, D. D., \& Swanson, D. H. (2006). Constructing the 'good mother': The experience of mothering ideologies by work status. Sex Roles, 54(7-8), 509-519.

Kanagawa, C., Cross, S. E., \& Markus, H. R. (2001). "Who am I?" The cultural psychology of the conceptual self. Personality and Social Psychology Bulletin, 27(1), 90-103.

Kitamura, R., Mokhtarian, P. L., \& Laidet, L. (1997). A micro-analysis of land use and travel in 5 neighborhoods in the San Francisco Bay area. Transportation, 24, 125-158.

Klöckner, C., \& Blöbaum, A. (2010). A comprehensive action determination model: toward a broader understanding of ecological behaviour using the example of travel mode choice. Journal of Environmental Psychology, 30, 574-586. 
Kuhn, M. H., \& McPartland, T. S. (1954). An empirical investigation of self-attributes. American Sociological Review, 19(1), 68-76.

Lois, D., \& López-Säez, M. (2009). The relationship between instrumental, symbolic and affective factors as predictors of car use: A structural equation modelling approach. Transportation Research Part A, 43, 790-799.

Mann, E., \& Abraham, C. (2006). The role of affect in UK commuters' travel mode choices: An interpretative phenomenological analysis. British Journal of Psychology, 97(2), 155176.

Markus, H., \& Nurius, P. (1986). Possible selves. American Psychologist, 41(9), 954-969.

Marsh, P., \& Collett, P. (1986). Driving passion: the psychology of the car. London: Jonathan Cape.

McMillan, T. E. (2005). Urban form and a child's trip to school: The current literature and a framework for future research. Journal of Planning Literature, 19(4), 440-456.

Miller, D. (2001). Car cultures. New York, NY US: Berg.

Mokhtarian, P. L., Salomon, I., \& Redmond, L. S. (2001). Understanding the demand for travel:It's not purely derived. Innovation, 14(4), 355-380.

Newman, L. S., Duff, K., Schnopp-Wyatt, N., Brock, B., \& Hoffman, Y. (1997). Reactions to the O. J. Simpson verdict: 'Mindless tribalism' or motivated inference processes? Journal of Social Issues, 53(3), 547-562.

Nigbur, D., Lyons, E., \& Uzzell, D. (2010). Attitudes, norms, identity and environmental behaviour: Using an expanded theory of planned behaviour to predict participation in a kerbside recycling programme. British Journal of Social Psychology, 49(2), 259-284.

ONS. (2010). Social Trends. Retrieved 5/8/2010, from http://www.statistics.gov.uk/cci/nugget.asp?id=2449

Ory, D. T., \& Mokhtarian, P. L. (2005). When is getting there half the fun? Modeling the liking for travel. Transportation Research Part a-Policy and Practice, 39(2-3), 97-123. 
Ouellette, J. A., \& Wood, W. (1998). Habit and intention in everyday life: The multiple processes by which past behavior predicts future behavior. Psychological Bulletin, 124(1), 54-74.

Oyserman, D., Fryberg, S. A., \& Yoder, N. (2007). Identity-based motivation and health. Journal of Personality and Social Psychology, 93(6), 1011-1027.

Pleck, J. H. (1985). Working wives/working husbands. Beverly Hills, CA: Sage.

Reisch, L. A. (2001). Time and wealth: the role of time and temporalities for sustainable patterns of consumption. Time \& Society, 10(2/3), 367-385.

Settles, I. H. (2004). When multiple identities interfere: the role of identity centrality. Personality and Social Psychology Bulletin, 30(4), 487.

Sparks, P., \& Guthrie, C. A. (1998). Self-identity and the theory of planned behaviour: A useful addition or an unhelpful artifice? Journal of Applied Social Psychology, 28(15), 13931410.

Sparks, P., \& Shepherd, R. (1992). Self-identity and the theory of planned behavior: Assessing the role of identification with "Green Consumerism". Social Psychology Quarterly, 55(4), 388-399.

Sparks, P., Shepherd, R., Wieringa, N., \& Zimmermanns, N. (1995). Perceived behavioural control, unrealistic optimism and dietary change: An exploratory study. Appetite, 24(3), 243-255.

Steg, L. (2001). Car use: lust and must. Instrumental, symbolic and affective motives for car use. Transportation Research Part F: Traffic Psychology and Behaviour, 4, 151-169.

Steg, L., Vlek, C., \& Slotegraaf, G. (2001). Instrumental-reasoned and symbolic-affective motives for using a motor car. Transportation Research Part F: Traffic Psychology and Behaviour, 4(3), 151-169.

Stets, J. E., \& Harrod, M. M. (2004). Verification across multiple identities: The role of status. Social Psychology Quarterly, 67(2), 155-171. 
Stokes, G., \& Hallett, S. (1992). The role of advertising and the car. Transport Reviews, 12(2), 171-183.

Stone, S. D. (2003). Workers Without Work: Injured Workers and Well-Being. Journal of Occupational Science, 10(1), 7-13.

Stryker, S. (1980). Symbolic interactionism: a social structural version. Menlo Park, CA: Benjamin Cummings.

Stryker, S. (1987). Identity theory: developments and extensions. In K. Yardley \& R. Honess (Eds.), Self and identity: Psychosocial perspectives (pp. 89-103). Oxford: John Wiley and Sons.

Stryker, S., \& Serpe, R. T. (1994). Identity salience and psychological centrality: Equivalent, overlapping, or complementary concepts? Social Psychology Quarterly, 57(1), 16-35.

Tabachnick, B. G., \& Fidell, L. S. (2001). Using multivariate statistics. Needham Heights, MA: Allyn and Bacon.

Thoits, P. A. (1992). Identity structures and psychological well-being: gender and marital status comparisons. Social Psychology Quarterly, 55, 236-256.

Triandis, H. C., McCuster, C., \& Hui, C. H. (1990). Multimethod probes of individualism and collectivism. Journal of Personality and Social Psychology, 59(5), 1006-1020.

Tsushima, T., \& Burke, P. J. (1999). Levels, agency, and control in the parent identity. Social Psychology Quarterly, 62(2), 173-189.

Verplanken, B., Aarts, H., van Knippenberg, A., \& van Knippenberg, C. (1994). Attitude versus general habit: Antecedents of travel mode choice. Journal of Applied Social Psychology, 24(4), 285-300.

Verplanken, B., \& Orbell, S. (2003). Reflections on past behavior: A self-report index of habit strength. Journal of Applied Social Psychology, 33(6), 1313-1330. 
Vignoles, V. L., Regalia, C., Manzi, C., Golledge, J., \& Scabini, E. (2006). Beyond self-esteem: Influence of multiple motives on identity construction. Journal of Personality and Social Psychology, 90(2), 308-333.

Watkins, D., Yau, J., Dahlin, B., \& Wondimu, H. (1997). The Twenty Statements Test: Some measurement issues. Journal of Cross-Cultural Psychology, 28(5), 626-633.

Yip, T. (2005). Sources of situational variation in ethnic identity and psychological well-being: a Palm Pilot study of Chinese American students. Personality and Social Psychology Bulleting, 31(12), 1603. 